\title{
El autonomismo en el sistema de partidos en Puerto Rico: Inercia institucional e ideología hegemónica*
}

\author{
Recibido: marzo 25 de 2008 - Aceptado: mayo 30 de 2008
}

\author{
Autonomism in Puerto Rico's partisan \\ system: institutional inertia and \\ hegemonic ideology
}

Ana Belén Benito Sánchez ${ }^{* *}$

Instituto Interuniversitario de Estudios de Ibero América

Universidad de Salamanca España

\section{Resumen}

La subordinación política en Puerto Rico parece constatar cierta "dependencia del rumbo", una suerte de inercia que evidencia la importancia de las instituciones en la orientación de las políticas a lo largo del tiempo. Pero ¿Cómo surgen estas instituciones? y ¿Por qué su continuidad? Una mirada al período formativo del sistema de partidos en Puerto Rico permite advertir que éste quedó envuelto en la maraña de la dinámica metropolitana (española primero y estadounidense después) convirtiéndose en un mero instrumento legitimador de la dependencia. El autonomismo, como ideología hegemónica, es resultado de la interacción de fuerzas e individuos mediatizados por las instituciones que han limitado el establecimiento de nuevos patrones políticos y cuya continuidad ha desembocado en el actual equilibrio estático.

\section{Palabras clave}

Liberalismo, Diseño Institucional, Autonomía, Puerto Rico.

\begin{abstract}
Political subordination in Puerto Rico seems to display some type of path dependency, a kind of inertia that shows the importance of institutions in leading policies through the years. But, how do these institutions arise? And, why do they remain? A glance at the formation period of the emerging party system, allows to understand that it remained wrapped in the jumble of the metropolitan dynamic (Spanish first and American later) turning into a mere legitimizing instrument of dependency status. Political autonomy as an hegemonic ideology is the result of the interaction of forces and individuals with the interference of institutions that have limited the establishment of new political patterns. These institutional constraints have promoted the current static balance.
\end{abstract}

\section{Key words}

Liberalism, Institutional Design, Political Autonomy, Puerto Rico.

\footnotetext{
"Esta investigación hace parte del proyecto Observatorio de Instituciones Representativas de la Universidad de Salamanca

** Candidata a doctora Programa Procesos Políticos Contemporáneos de la Universidad de Salamanca, España. Licenciada en Derecho, Magister en Estudios Latinoamericanos del Instituto de Iberoamérica. Universidad de Salamanca. Magister en Administración Pública Universidad de Puerto Rico. Investigadora del Instituto de Iberoamérica en el Observatorio de Instituciones Representativas. Proyecto "Legislatina": Estudio de los parlamentos latinoamericanos en perspectiva comparada. En 2009, becaria del Ministerio de Asuntos Exteriores-AECID en FLACSO-República Dominicana. Correo electrónico: anabeleta@usal.es
} 


\section{Introducción}

La subordinación política en Puerto Rico, parece constatar cierta "dependencia del rumbo", una suerte de inercia que evidencia la importancia de las instituciones en la orientación de las políticas a lo largo del tiempo. Pero ¿Cómo surgen estas instituciones? y más importante ¿Por qué su continuidad? Una mirada al período formativo del sistema de partidos en Puerto Rico permite advertir que éste quedó envuelto en la maraña de la dinámica metropolitana (española primero y estadounidense después) y como consecuencia de su especial contexto colonial, el sistema de partidos fue siempre un mero instrumento legitimador del arreglo de la dependencia y en la actualidad, un canal que permite la expresión de grados de satisfacción con el propio sistema (Anderson 1998:17).

El autonomismo ha sido la ideología hegemónica en la dinámica política puertorriqueña desde que se inició la competencia partidista. El propósito de esta investigación es mostrar que el autonomismo es el resultado de la interacción de fuerzas e individuos mediatizados por las instituciones que han limitado el establecimiento de nuevos patrones políticos y cuya continuidad parece haber desembocado en el actual equilibrio estático. El estudio se centrará en explicar la influencia de los factores geopolíticos y estratégicos (contexto colonial centro-periferia) y cómo éstos afectaron al proceso político interno, delimitando la estrategia autonomista y condicionando el devenir de la reforma política en Puerto Rico. La especificidad radica en abordar el estudio de caso desde la perspectiva teórica del Nuevo Institucionalismo Histórico (March y Olsen 1984; Peters 2003; Thelen y Steinmo 1992). Se analizará cómo los cambios en el contexto político modelaron los objetivos y las estrategias de los actores políticos y cómo las variables institucionales de nivel intermedio (sistema electoral, restricciones censales, caciquismo burocrático, violencia política), condicionaron la solución final de "falsa apariencia de soberanía" en 1897 con la concesión del régimen autonómico (bajo soberanía española) y en 1952 con la proclamación del Estado Libre Asociado (bajo soberanía estadounidense).

Las instituciones definen el marco en el que la política tiene lugar y afectan al devenir histórico, pues determinan las preferencias de los actores políticos, la distribución de poder entre ellos y las reglas del juego. Cambios en el contexto económico, social o político pueden alterar la aparente estabilidad (o inercia institucional), propiciando la reforma y superando las fricciones institucionales. La elección del enfoque histórico, para explicar la estrategia moderada seguida por el Partido Autonomista de Puerto Rico en el XIX y el Partido Popular Democrático en el XX, permitirá entender la subordinación política actual, al estudiar las decisiones iniciales, los compromisos institucionalizados que de ellas surgieron y cómo éstos determinaron las decisiones posteriores.

\section{I- Bajo dominación española}

El objetivo de esta sección es mostrar la vulnerabilidad política de la Isla en relación a la variable geopolítica y la interacción "matrizperiferia". El análisis de la senda histórica del autonomismo evidencia cómo los actores domésticos quedaron presos de los acontecimientos peninsulares. El seguimiento de la vida de las instituciones coloniales será un indicador preciso de la influencia de los vaivenes políticos en España.

A pesar de que los gobiernos liberales fueron más condescendientes a la hora de conceder autonomía, no pasaron de ser meros intentos de abaratar los costes de la administración ultramarina, de tal forma que los intereses peninsulares eran más fuertes que la defensa de la doctrina liberal para la Isla. Estas contradicciones del liberalismo español constituyeron un "punto de veto" (Immergut 1992), identificados éstos por el Nuevo Institucionalismo Histórico como áreas de vulnerabilidad institucional que provocaron el fracaso de la innovación política. 


\section{La política colonial en puerto rico: el devenir de la reforma política}

La singularidad del liberalismo español decimonónico ha sido destacada ampliamente por la literatura (Suárez Cortina 1999). Las dos concepciones del Estado moderno: absolutista y liberal, convivían de forma nada pacífica en la vida política decimonónica. La lucha por el poder tendría reflejo en la política colonial: distintos planteamientos que se reflejaron en cambios en el esquema político de Puerto Rico.

La Constitución de Cádiz de 1812 permitió la representación de la Isla en las Cortes Nacionales, instituyó el carácter electivo de los Ayuntamientos y la Diputación Provincial y garantizó la igualdad de trato ante la ley. Durante el trienio liberal español (1820-1823), los diputados puertorriqueños Quiñones y Varela presentaron un proyecto de descentralización y autonomía política que fue aprobado en las cortes españolas, pero el retorno de Fernando VII frustró su puesta en vigor y comenzó otra etapa de restricciones y persecuciones de los liberales en la Isla conocida como la "Década Ominosa". En 1865 el Ministerio de Ultramar dio inicio a los trabajos preparatorios de la futura reforma en las provincias de Cuba y Puerto Rico. El fracaso del proyecto encendió el movimiento revolucionario en Cuba, mientras que en Puerto Rico, el descontento por la tardanza de las tan ansiadas reformas descartó las armas y optó por la reivindicación política pacífica-conformista que caracterizó el siglo XIX. Con la Revolución Liberal "La Gloriosa" de 1868 resurge en la Península y en la Isla un clima favorable para las aspiraciones de los reformistas criollos. La consecuencia inmediata en la colonia fue la supresión de las facultades omnímodas; facultades extraordinarias ilimitadas otorgadas por Real Decreto a los Gobernadores de la Isla y respaldo legal de su actuación despótica y arbitraria y por la intención de regenerar la vida política, aquí seis días después de la revolución "La Gloriosa" tiene lugar en la isla el "Grito de Lares", la única revolución armada en Puerto
Rico que llegó a proclamar su independencia el 23 de septiembre de 1868.

El Ministro liberal de Ultramar Manuel Becerra diseña un proyecto en el que el cuerpo rector era una Asamblea con amplias potestades, lo que provocó el rechazo de las fuerzas políticas españolas y desencadenó su renuncia. Le sustituye Moret Prendergast, bajo cuyo mandato se aprueba la Ley Provincial de 1870. Esta era una reforma más conservadora y restrictiva que rechazaba cualquier tipo de autonomía decisoria de la Isla. Con la I República Española por fin llegan las anheladas reformas y se materializa en un proyecto de Constitución Federal, que de implementarse, convertiría a Puerto Rico en un Estado soberano y la isla disfrutaría de una capacidad de autogobierno propia de los estados federales, pero la recién nacida República Española contaba con numerosos enemigos en la Península y pronto un nuevo rumbo en la orientación política española trajo la Restauración y la subida al trono de Alfonso XII. Este esquema constitucional más restrictivo dio paso a una reforma de la Ley Municipal y Provincial de Puerto Rico, donde los alcaldes eran elegidos de entre una terna de candidatos y la Diputación Provincial pasaba a ser un mero órgano consultivo. El nuevo Ministro de Ultramar Víctor Balaguer, un declarado enemigo de las innovaciones, restituye en su cargo al Gobernador Laureano Sanz, quien prohibirá las sociedades políticas por atentar contra la unidad nacional y relevará al personal de la Diputación Provincial, alcaldes y modificará restrictivamente las condiciones electorales (Dálzina 1995: 114).

Años más tarde, el Ministro de Ultramar, Antonio Maura Montaner, propone en 1892 conceder a las Islas un mayor número de facultades y modificar el régimen electoral para garantizar la presencia de las minorías en las instituciones de carácter local; medida que ponía en peligro el monopolio del Partido Incondicional Español en Puerto Rico. El miedo a la independencia que inspiraba la autonomía frenó la reforma y a esta tentativa le siguió la llamada 
Ley Abárzuza, mucho más restrictiva, debido a que reforzaba el poder del Gobernador. Forzada por las circunstancias del conflicto internacional que se avecinaba con los Estados Unidos y por acontecimientos fortuitos como el asesinato del Presidente Cánovas del Castillo, España decide conceder el tan esperado régimen especial para sus territorios de Ultramar. El 25 de noviembre de 1897 un Real Decreto otorgaba la igualdad jurídica y política a los habitantes de Puerto Rico y el sufragio universal. La reforma consagró las aspiraciones isleñas de sustituir a los funcionarios españoles afectos al régimen, por un nuevo cuadro de administradores autonomistas y puertorriqueños. La Carta Autonómica finalmente atendía, aunque no satisfacía plenamente, las expectativas descentralizadoras de los criollos.

\section{Surgimiento y evolución de los partidos políticos en puerto rico en el siglo XIX}

Se distinguen tres tendencias: el españolismo, la puertorriqueñidad y la separatista. La alineación política en torno a los liberalesreformistas estaba compuesta por la mayoría de criollos y algunos peninsulares descontentos con el régimen colonial. La tendencia españolista defendida por los conservadores, tenía en sus filas a los administradores coloniales y mercantilistas, en su mayoría españoles. La tendencia separatista se caracterizó por su presencia discreta a lo largo del siglo XIX, interrumpida por breves episodios de pronunciamientos $\mathrm{y}$ levantamientos revolucionarios (Bayrón Toro 1988). Los partidos políticos puertorriqueños surgieron en 1870: el Partido Conservador y el Liberal Reformista. Con la llegada de la I República Española en 1873 se inició en Puerto Rico un período de libertades públicas y reformas políticas gracias al apoyo de los diferentes gobernadores pro-liberales que favorecerían la causa autonomista. Los liberales cambian el nombre del partido a Partido Federal Reformista y pactan con el Partido Republicano Federal de España. En este clima adverso para los conservadores, surge el Partido Incondicional
Español el 15 de agosto de 1880, cuya base fundamental fue preservar la integridad nacional en Puerto Rico (Pagán 1961: 291). La situación de este partido dependió del apoyo gubernamental y de las artimañas electorales de algunos gobernadores. Durante el gobierno de Laureano Sanz, época de gran represión política y social, el partido disfrutó de gran apoyo institucional. Sin embargo, con el General Baldrich, fueron vistos como enemigos y adversarios del Gobierno Provincial. No se dio propuesta electoral programática, sino oposición a cualquier posibilidad de autogobierno que pudiera desembocar en la ruptura de los lazos de unión con España.

El Partido Liberal, ahora denominado Partido Autonomista Puertorriqueño, busca la mayor descentralización dentro de una unidad nacional. En él conviven dos posturas enfrentadas: la autonomía administrativa $V_{S}$ autonomía política. La primera busca fortalecer la vida política insular con la concesión de facultades legislativas (Cruz Monclova 1955:35). En la segunda, a pesar de que la independencia no se muestra abiertamente en el programa político, es el camino inevitable al que conduciría la madurez en la autogestión de los asuntos propios. El Partido Autonomista acoge como postura oficial la primera: una autonomía matizada que no implica una ruptura drástica de las estructuras gubernamentales y en la que el ejercicio de los derechos políticos no produce perturbaciones peligrosas: "... no aspirando nosotros a tanta cantidad de autonomía, antes bien, conformándonos con la descentralización administrativa, sin tocar en nada lo restante..." (Domínguez 1887:10). La solución al régimen colonial debería provenir de la evolución en las formas de gobierno hasta llegar al gobierno propio. Puerto Rico resolvería las cuestiones de carácter local y el Gobernador sería nombrado por la Metrópoli y la Cámara insular por sufragio popular, pero sin capacidad legislativa. El autonomismo del XIX, sentó las bases programáticas del autonomismo del XX y XXI: se hacían valer los mismos miedos y visiones 
catastrofistas de la independencia que habían protagonizado las campañas posteriores que marcarían el modo pacífico de la reivindicación y reforma y definiría el modelo institucional.

La caída de la República impidió la realización de las medidas progresistas dictadas para la Isla y causó un gran impacto en la organización liberal, hasta el punto que muchos de sus dirigentes se retiraron de la vida pública (García Ochoa 1982). A partir de 1874 son los conservadores los que dominan el panorama político en Puerto Rico respaldados por las circunstancias políticas en la Península. En plena crisis del Partido Liberal Reformista, se recrudece el debate entre las dos facciones para definir el autonomismo con ocasión de la declaración del Gobierno de España de aplicar a las Antillas una política asimilista. La crisis de los liberales se vio acrecentada por las persecuciones a los autonomistas que tuvieron lugar bajo la administración del Gobernador Romualdo Palacio. Cansados de esperar las reformas prometidas, los liberales autonomistas decidieron enviar una comisión con el fin de lograr acuerdo con algún partido demócrata peninsular que defendiera estas pretensiones autonomistas. En 1897 la comisión liderada por Luís Muñoz Rivera alcanza un acuerdo con el Partido Liberal Fusionista Español presidido por Sagasta, quien se compromete a llevar a cabo la descentralización administrativa y otras medidas tan importantes como el sufragio universal, rebaja en la cuota electoral y la extensión de los derechos políticos de la Península. Se sientan así las bases del régimen autonómico a cambio de apoyo en las Cortes. En febrero de 1897 los liberales autonomistas pasan a denominarse Partido Liberal Fusionista Puertorriqueño. En ese año, los contrarios al pacto fundan el Partido Autonomista Histórico u Ortodoxo. También se produce una escisión en las filas conservadoras donde un grupo de disidentes exigen al Partido Incondicional que se adecue a las nuevas circunstancias. Al ser expulsados fundan el Partido de Izquierda Progresista Incondicional posteriormente cambiando el nombre a Partido Oportunista.
Nuevamente los acontecimientos políticos en la Península desencadenan oportunidades políticas para la Isla. El 8 de agosto de 1897 Cánovas del Castillo es asesinado por un anarquista y asume la presidencia del Gobierno Mateo Sagasta. De esta manera, las aspiraciones autonomistas que se fueron gestando a lo largo de todo el siglo XIX, se ven materializadas el 25 de noviembre de 1897 , fecha en la que se otorga oficialmente el régimen autonómico a Puerto Rico.

\section{Elecciones en puerto rico (1869-1898): control y manipulación}

En esta investigación el sistema electoral es contemplado como una variable independiente que explica determinadas características del sistema político, entre ellas, la forma en que afecta al Partido Autonomista como organización y a su estrategia electoral. El panorama electoral en España se vio afectado por las luchas y cambios de poder entre liberales y conservadores en el siglo XIX. La alternancia de la restauración favoreció la reforma electoral con fines partidistas (Varela, 2001). En el período eleccionario estudiado son tres las leyes electorales que se dictan en España: la Ley Electoral de 1870, la más democrática y extensiva del derecho del sufragio ( $24 \%$ de la población española); la Ley Electoral de 1878 (5\% de la población española) que rediseñó las circunscripciones con el fin de ahogar el voto urbano más progresista; y la Ley de 1890 que tratará de paliar el fraude masivo producto de la alternancia; sin embargo, la extensión del sufragio no pudo compensar las deficiencias de una cultura política en la que el caciquismo y el control de las autoridades locales favorecían el miedo y la abstención (Garrido, 2004:60).

La alternancia entre liberales y conservadores en España (1875-1900), no tuvo reflejo en los resultados electorales en la Isla, debido a que los conservadores dominaron el panorama político. De las trece elecciones, sólo las de 1871 y 1873 (correspondientes al sexenio revolucionario) se ejecutaron de acuerdo a la legislación vigente en 
España y sin modificaciones. El resto, por medio de decretos, se restringieron las condiciones electorales. La Ley Electoral de 1890 de corte liberal, consagraba el sufragio masculino universal, sin embargo, las elecciones en Puerto Rico se ejecutaban de acuerdo a la Ley Electoral de 1878 , la más restrictiva y conservadora que condicionaba el derecho de voto a los españoles mayores de 25 años que pagaran una cuota de 25 pesos anuales. Las restricciones censales fueron utilizadas para contener el avance de los liberales autonomistas. En 1873, con el establecimiento de la I República Española, el censo alcanza una cifra récord de 46.042 electores. Trece años después, en plena Restauración y bajo el gobierno conservador de Cánovas, el censo de electores puertorriqueños se redujo a 2.492, sobre una población de 800.000 habitantes. No sería hasta 1898 , con un gobierno favorable en Madrid, cuando se aprobó el sufragio cuasi-universal y el censo se elevó a 165.068 electores inscritos. A pesar de las concesiones electorales y sus efectos sobre el censo de la Ley Maura de 1892, la violencia política y el caciquismo burocrático condicionaban la estrategia del Partido Autonomista, que se retiró de la arena pública optando por el retraimiento electoral. Los conservadores puertorriqueños lograron la destitución de los Gobernadores proliberales Baldrich en 1871 y Simón de la Torre en 1872 y llegaron a acuerdos con las autoridades para la elección de "cuneros": españoles no residentes en Puerto Rico. En 1872, nueve de los quince representantes son españoles no residentes en la Isla.

El efecto de los cambios en el contexto político peninsular sobre las estrategias de los partidos en la Isla se aprecia claramente entre 1873 y 1876 . En 1873 con la proclamación de la I República cuando los conservadores se retiran de la arena electoral y los liberales obtienen los 15 representantes a cortes. Un año después cae la República y con la vuelta al absolutismo serán los liberales los que decidan no participar, obteniendo esta vez los conservadores los 15 representantes a cortes generales. Los triunfos del Partido Autonomista coinciden con 1) el Gobierno liberal del período revolucionario que siguió a "La Gloriosa", 2) la I República Española, y 3) en 1898 tras la concesión del régimen autonómico. En estos períodos, las restricciones censales son menores y los Gobiernos se desarrollan en un clima de mayor libertad y estabilidad. Sin embargo, los liberales no se vieron exentos del uso de la manipulación y el control de las elecciones, traicionando así sus aspiraciones de transparencia y libertad que perseguían en la Península.

En 1872 el fraude orquestado por el Gobernador Gómez Pulido desata un clima de protestas y la convocatoria de una segunda elección en la que los autonomistas consiguieron esta vez 14 representantes (frente a los 7 anteriores). En 1871, el Gobernador pro-liberal Baldrich rehúsó celebrar elecciones para la designación de los representantes municipales y provinciales y por medio de decretos se restringe la Ley Electoral de 1870 (la más democrática y extensiva del sufragio), consagrando el cunerismo y la elección manipulada de los candidatos oficiales. En 1886, tras las irregularidades en las elecciones pasadas, la cúpula del Partido Liberal renuncia, ocasión que es aprovechada por los liberales españoles para convocar al mes siguiente elecciones. Sin tiempo para reorganizarse, el Partido es víctima de esta nueva estrategia de manipulación.

La Ley Electoral Maura de 1892 dictada para las elecciones en los territorios de Ultramar, elevó el censo de votantes en Puerto Rico a 8.700, una medida aperturista que se vio eclipsada por los efectos devastadores de la violencia de los años precedentes. La caída de la I República tendría catastróficas consecuencias en la Isla. El retorno de Laureano Sanz, uno de los gobernadores más violentos, dio inicio a una época de represión y persecución que separaría a los liberales de las alcaldías, las escuelas y otras esferas de la vida pública. Estas circunstancias, además de las restricciones electorales impuestas por Decreto, condicionaron la decisión de no acudir a las urnas. 
La violencia auspiciada por el Gobernador Romualdo Palacios desde 1887, creó un clima de terror que mantendría a los autonomistas alejados de la vida pública. Así lo reflejaron las dos siguientes elecciones, en las que no participaron. Teniendo en cuenta las diferencias en los resultados por partidos y los representantes que éstos obtuvieron, la competitividad fue baja. De los 15 representantes a cortes generales (16 desde 1893), las victorias oscilaron de 15-14 representantes del partido ganador a 0-1 representantes de la oposición (16-0 desde 1893). No hay por tanto competitividad parlamentaria y el partido ganador lo hizo por mayoría absoluta. En las elecciones de 1879, 1884 y 1886, el nivel de competitividad aumentó, obteniendo los autonomistas 4, 3 y 3 representantes respectivamente. En estos períodos no hubo incidentes significativos de violencia política y represión contra los autonomistas, pudiendo incidir positivamente en la elección, lo que corroboró la relación significativa de esta variable. En cuanto a la volatilidad, las preferencias de los actores se mantuvieron estables. El voto conservador fue constante y proporcional al censo en cada elección. Puesto que las restricciones censales fueron utilizadas para privar al Partido Autonomista de su base de apoyo, el mayor número de votos de los liberales autonomistas no procedió de la proporción de votantes abiertos a la persuasión, sino de la ampliación del censo y el número de electores.

El proceso eleccionario en el Puerto Rico decimonónico estuvo caracterizado por el dominio conservador gracias al control gubernamental en Madrid y el caciquismo. La represión, el fraude electoral y las restricciones censales privaron a los liberales autonomistas de su base de apoyo. La oligarquía terrateniente y sus redes en Madrid fomentaron el sistema de cuneros, vigente hasta 1892. La concesión del sufragio cuasi-universal en la Isla en 1897, supuso el logro de una de las principales aspiraciones de la lucha autonomista. La victoria del Partido Autonomista, se vio favorecida por la coyuntura favorable de la crisis del café (Cubano, 2000). La caída de precios desarticuló las redes clientelares de los incondicionales y los autonomistas ganaron por mayoría absoluta. En el nuevo diseño institucional de la Carta Autonómica de 1897, el Parlamento insular tenía a su cargo la potestad de reglamentar el proceso electoral. Finalmente los autonomistas isleños podrían influir en ciertos aspectos del meta-nivel "reforma electoral" descrito por Schedler (2002). De tal manera que el Reglamento Electoral de 1898 es una adaptación de la Ley Electoral de la Península de 1890, con un sufragio cuasi-universal. En las elecciones de 1898 concurrieron cuatro partidos: el Liberal, Ortodoxo, el Incondicional y el Oportunista. Los liberales autonomistas alcanzaron la mayoría en las cortes españolas y los órganos autonómicos, la Asamblea Legislativa y Consejo de Administración. Sin embargo, estas instituciones del régimen autonómico no llegaron a alcanzar sus fines, puesto que el 25 de julio de 1898 las tropas norteamericanas invadieron Puerto Rico y se produjo el cambio oficial de soberanía.

\section{II- Bajo dominación Estadounidense}

El objetivo de esta sección es mostrar cómo los cambios en el contexto socioeconómico y político influyen en las instituciones existentes, permitiendo la adaptación y redefinición los intereses y estrategias de los actores políticos locales. En esta segunda etapa, la dinámica electoral de la Isla determinó el ofrecimiento de una u otra solución al status de Puerto Rico. En 1952 se oficializó el Estado Libre Asociado, un outcome político inevitable producto de factores institucionales que han restringido las opciones de los actores. El autonomismo se reveló como la opción maximizadora de beneficios forzada por las instituciones, lo que en la tradición cultural puertorriqueña se conoce popularmente como "lo mejor de los dos mundos".

Una descripción de la lógica económica permitirá entender la importancia de los programas económicos en el éxito electoral del Partido Popular Democrático PPD como defensor oficial del autonomismo. No fue hasta 
1968 cuando se produjo el cambio de un sistema de partido dominante a uno genuinamente bipartidista. La dependencia económica arrasó los programas partidistas hasta la confusión y el empate técnico de las fuerzas políticas hasta el inmovilismo. El determinismo institucional se presentó como obstáculo para el cambio político (Thelen y Steinmo 1992).

\section{Política colonial: lógicas estratégicas, económicas e ideológicas}

La historia política estadounidense en el período objeto de estudio estuvo presidida por una variedad de acontecimientos decisivos: la transformación en potencia mundial, I y II Guerra Mundial, la Gran Depresión, Roosevelt y el Nuevo Trato, el "macartismo" y la Guerra Fría; todos ellos tendrían consecuencias en el diseño políticopartidista en Puerto Rico y serían la razón de las diferentes estrategias de adaptación/reacción de los partidos políticos en la Isla. La Guerra Hispanoamericana marcaría el punto de inicio del imperialismo estadounidense. Así, Puerto Rico fue el bastión militar, económico y político en el siglo XIX y su valor estratégico tras el cambio en el equilibrio de poder internacional, sería objeto de deseo del Departamento de Guerra de los Estados Unidos (Estades Font 1988:37). La literatura resaltó el recibimiento sin apenas, oposición de las tropas y funcionarios norteamericanos (Luque de Sánchez 1980). La concesión del régimen autonómico había llegado demasiado tarde y las promesas de cambio político y libertad eran recibidas entre el fervor y el entusiasmo. Dos años después, la Ley Foraker organiza el gobierno civil de Puerto Rico: un ejecutivo (Gobernador elegido por el Congreso de EEUU) y un pseudo-legislativo (Cámara de Delegados asistida por un Consejo Ejecutivo en la que sólo la mitad de sus miembros eran puertorriqueños). En 1917, en plena Guerra Mundial, La Ley Jones redefinió las relaciones con la Isla, separando en apariencia los tres poderes, debido a que las dos Cámaras locales Congreso y Senado- legislarían bajo la supervisión del Gobernador y el Congreso estadounidense, con derecho de veto sobre sus resoluciones. Treinta años después la Ley 600, en un intento de oficializar y organizar un gobierno constitucional en Puerto Rico, permitió la elección del Gobernador y la celebración de una Asamblea Constituyente. Nacía así el Estado Libre Asociado (ELA), que otorgaba el control del gobierno local, pero dejaba intactas el resto de las disposiciones de la Ley Foraker y Jones. En este reducido escenario de falsa apariencia de soberanía, los partidos políticos isleños pasarían a ser simples maquinarias de patronazgo interesadas en administrar la limitada estructura del gobierno local (Meléndez Vélez 1998:5).

La política migratoria es otra de las importantes expresiones de continuidad del pasado con efecto sobre el sistema de partidos que se observan en este período. En el siglo XIX, la política de inmigración tuvo como finalidad blanquear la Isla y mitigar las aspiraciones revolucionarias de los criollos. Las filas del Partido Incondicional se llenaban de españoles recién llegados de la metrópoli, pero también de los que huían de las guerras de independencia del continente. Puerto Rico pasaba así a ser un reducto de conservadurismo nostálgico. En la década de los cuarentas se decidió exportar la sobrepoblación y la pobreza de la Isla. De esta manera se privaba de su base al Partido Socialista, en peligroso avance electoral desde 1917 y en el poder desde 1932 a 1940, a la vez que se sofocaban los potenciales reclamos de clase y soberanistas-revolucionarios. La política de subsidios, salario mínimo y medidas antilatifundistas del New Deal, favorecieron el ascenso electoral del autonomista Partido Popular Democrático, que cooptó a este nuevo sector de proletariado urbano y campesinos. La burguesía comercial y empresarial favorecida por el desarrollismo de subsidio federal, compartía así los mismos intereses políticos a la vez que se difuminaba la lucha de clases.

También hubo continuidad en cuanto a la violencia política. La pragmática aceptación de la solución intermedia que oficializó la tradición 
autonomista hegemónica, precipitó la radicalización violenta del independentismo puertorriqueño. La década de los treinta y los cincuenta, estaría plagada de atentados terroristas, asesinatos políticos y el encarcelamiento del dirigente nacionalista Pedro Albizu Campos durante 22 años. La incapacidad del nacionalismo para afrontar con éxito las convocatorias electorales lo llevarían a adoptar estrategias de retraimiento, combinada con acciones esporádicas de violencia perpetradas por el Ejército de Liberación Nacional (Reinares 1995:73). Un nuevo partido independentista de orientación socialdemócrata y favorable a la participación electoral surgiría en la década de los 50, formando parte del panorama político en la actualidad. El "macartismo" y las persecuciones políticas tuvieron su particular expresión en Puerto Rico a través de la llamada "Ley de la Mordaza", aprobada por el gobierno del PPD en 1948, que convertiría en delito la pertenencia a partidos subversivos. De nuevo el oficialista Partido Popular Democrático, se beneficiaba de la represión de sus adversarios políticos y servía de instrumento de control y pacificación al servicio de los intereses políticoeconómicos de la metrópoli.

Más allá del relato histórico, autores como Grosfoguel (1999) han explicado las concesiones políticas y económicas como parte de una estrategia de los EEUU para generar una hegemonía ideológica en las clases subalternas que ha minado el potencial reclamo soberanistaindependentista. Mientras que en otras ocupaciones militares en el Caribe, como Cuba, Nicaragua, República Dominicana y Haití, EEUU desarrolló alianzas autoritarias con los terratenientes y/o élites político-militares para proteger sus intereses. La estrategia en Puerto Rico se basó en hacer concesiones democráticas a las clases trabajadoras y medias liberales en contra de los terratenientes cafetaleros (Grosfoguel 1999: 22). El Departamento de Estado y el de Interior fueron los promotores de las mayores concesiones: elección democrática del gobernador de la Isla, concesión del sufragio universal, transformación económica mediante la inversión extranjera masiva (principalmente farmacéuticas)... Un modelo desarrollista apoyado con grandes transferencias federales, una emigración masiva y oficializada de la fuerza de trabajo marginada a los centros urbanos norteamericanos, vendieron al mundo una imagen exitosa del modelo económico puertorriqueño. La lógica simbólica fue la razón de que ante las sucesivas crisis, EEUU duplicara la asistencia federal para garantizar la legitimidad y el éxito del modelo. Y así seguiría siendo en la década de los setentas y ochentas, incluso cuando la reducción de la asistencia social era la receta neoliberal de los organismos internacionales para el resto de América Latina. Ya en los noventas, las élites políticas norteamericanas, redescubren un Puerto Rico costoso por las transferencias federales y las exenciones fiscales. Un posible triunfo de la anexión, resultaba una opción costosa para el Estado norteamericano en términos de transferencias, pero también políticamente desestabilizante, ante la incorporación de un estado de cultura afrolatina e hispanohablante (Gosfoguel 1999: 27).

La estrategia económica es sin embargo, para otros autores, la que ha definido todo el proceso de renegociación del pacto colonial. El desarrollismo puertorriqueño fue el proyecto político de reestructuración de la dominación colonial, que articulaba los intereses de la clase burguesa dominante, presentados como intereses de la sociedad general (Pantojas 1990). Mientras que en América Latina el impulso desarrollista vino de la burguesía local. En Puerto Rico el empuje procedía de los grupos metropolitanos, que tras la Gran Depresión, vieron en la expansión del estado colonial una manera de mantener el control de la Isla. El autonomismo se convertía, así, en la fórmula para extender las bases de la legitimación de la dominación, permitiendo la incorporación de elementos locales en el aparato estatal. Con la Carta Autonómica de 1897 tomaron el control del poder los hacendados cafetaleros, pero tras la invasión estadounidense fueron relegados del control local. Surgió así la 
nueva élite burguesa azucarera que se aliaría con las poderosas corporaciones azucareras de Estados Unidos. La Gran Depresión tuvo efectos devastadores en la Isla, afectando especialmente al sector azucarero. La dimensión política de la crisis resultó en el cuestionamiento del régimen colonial, un espacio de oportunidad en el que surgiría con fuerza el Partido Nacionalista, protagonista en la década de los 30 de exitosas huelgas generales y boicots de las compañías norteamericanas. Su base social estaba compuesta por la pequeña burguesía local, los sectores afectados por la crisis, el proletariado rural y los miles de desempleados de la Isla. Los trabajadores del azúcar lideraron la crisis política en este período y tras el pacto entre Republicanos y Socialistas -considerado una traición por parte de sus bases- apoyaron la estrategia del Partido Nacionalista. Se produjo así, la colaboración entre dos fuerzas potencialmente revolucionarias que despertó los temores de las autoridades coloniales. El fin de la alianza nacionalista-trabajadores se logró gracias a la represión oficial y a través de los programas de bienestar que rompieron definitivamente el consenso entre clases. En 1940, el colapso de la economía azucarera en la Isla, provocó también el colapso de los partidos tradicionales. El PPD recogió los votos de un electorado disperso y de las clases trabajadoras descontentas. Con el PPD en el gobierno, las agencias federales en la Isla encargadas de implementar las políticas del New Deal fueron ocupadas por los autonomistas bajo la dirección de Luís Muñoz Marín, amigo personal de Roosevelt. Se creó así un sistema paralelo de welfare dominado por el caciquismo y el reparto de puestos de trabajo. El desarrollismo populista del PPD no cuestionaba el orden legal existente: un partido que no era antiimperialista, ni nacionalista ni comunista. Sus intereses coincidían con los intereses de la burguesía de EEUU.

La autonomía fiscal permitió al Estado Libre Asociado en 1952 eximir al capital estadounidense de pagar impuestos locales y beneficiarse de subsidios y salarios bajos. La asociación permanente les aseguraba que el capital estadounidense permaneciera dentro de la esfera del Estado metropolitano y la estabilidad necesaria para una inversión segura.

\section{Elecciones en puerto rico: readaptación al contexto y estrategias}

La Constitución Autonómica de 1898 y la Constitución del Estado Libre Asociado de 1952 fueron las dos reformas políticas que oficializaron la solución intermedia y que definirían la historia política puertorriqueña. La primera, diseño del liberal autonomista Luís Muñoz Rivera y la segunda obra de Luís Muñoz Marín (hijo del primero). En este especial contexto de dependencia, la dinámica electoral se acercó más a lo que Nohlen ha categorizado como "elecciones semicompetitivas (Nohlen 1994:17): legitimar las relaciones de poder existentes, mejorar la imagen ante la opinión pública internacional (presiones imperialistas primero y anticoloniales después), relajar las tensiones internas (permitiendo manifestaciones de las fuerzas opositoras, limitadas por los efectos perversos del sistema electoral) y generar reajustes en el aparato del poder a fin de afianzar el sistema.

El proceso eleccionario del siglo XX fue más complejo que el decimonónico, sin embargo, los dos coincidieron en el resultado final: el triunfo de la opción partidista que cuenta con el apoyo de la metrópoli y que finalmente definiría la reforma política autonómica. Comparando los dos períodos, la relación sigue un patrón de causalidad circular. La Ley Foraker de 1900 redistribuyó las circunscripciones electorales plurinominales uniformes mayoritarias, limitando las posibilidades de los partidos de la oposición. El efecto de las peculiaridades del sistema electoral sería la progresiva eliminación de las fuerzas políticas hasta la conformación de un sistema bipartidista típico (y que en el siglo XXI por el estancamiento y empate técnico pasaría a ser bipartidista con alternancia pragmática) hasta la consecución del segundo de los hitos autonómicos, proceso en el que se distinguen tres etapas: 
$1{ }^{a}$ Etapa: Coaliciones y Alianzas (19001902)

Se produce el primer intercambio de posturas. Los liberales, partidarios de un autonomismo en el que no se discutían los lazos con la metrópoli, serán ahora el Partido Federal Americano, quienes a pesar del nombre, representan la versión más puertorriqueñista de la anexión. Por el contrario, los ortodoxos, serán ahora el Partido Republicano Puertorriqueño, partidarios de la anexión y representantes de la facción conservadora tras la desaparición de los Incondicionales. El Partido Federal Americano decreta el retraimiento electoral en estas dos contiendas para mostrar su oposición al diseño de las circunscripciones. El resultado será la victoria de los Republicanos. En este período continúan los episodios violentos entre las dos opciones partidistas. Los atentados de las llamadas "turbas republicanas" contra líderes federales, provocan el exilio de Luís Muñoz Rivera a Nueva York. En estas fechas aparece el Partido Obrero Socialista dirigido por el gallego Santiago Iglesias Pantín, que adopta el programa del Partido Socialista de Estados Unidos.

\section{$2^{a}$ Etapa: Coaliciones y Alianzas (1904- 1936)}

A- Baja competitividad (1904-1910): El nuevo Gobernador de la Isla recibe instrucciones de acabar con el dominio de los republicanosanexionistas. Surge la alianza entre partidos y se materializa en el Partido Unión de Puerto Rico, con la independencia como meta principal. El rechazo del Partido Republicano a formar parte de la alianza divide a los antiguos autonomistas: los Republicanos puertorriqueños se integran en las filas del Partido Republicano Nacional y pasan a ocupar la derecha en el espectro ideológico, mientras que los Federales ocuparían el centro. El Partido Socialista forma parte de esta alianza que vence por mayoría absoluta en 1904, 1906, 1908 y 1910.

B-Alta competitividad (1912-1936): Comienza un nuevo período que tiene su origen en la enmienda de la Ley Electoral que permite la representación de las minorías y que favorece al Partido Republicano. El fracaso electoral del Partido de la Independencia, surgido de la escisión de un grupo de unionistas, hace reconsiderar a la cúpula del Partido Unión de Puerto Rico acerca del status de la Isla y deciden optar por la autonomía como paso previo a la independencia. La competitividad va en aumento y los republicanos van escalando puestos hasta convertirse en la segunda fuerza política junto con el Partido Socialista. La diferencia entre los representantes conseguidos por el Partido Socialista (4) y Republicano (9) a pesar de la poca diferencia de votos $(59.140$ y 63.845 respectivamente) dan idea de la desproporcionalidad del sistema. Las elecciones de 1920 se desarrollan entre sospechas de fraude por el apoyo del gobernador a los unionistas. En 1924, la Alianza Unión de Puerto Rico, que constituye la oficialización electoral de la solución intermedia, o tercera vía que sería el futuro Estado Libre Asociado de 1952, abandona la independencia para perseguir oficialmente la autonomía, lo que provoca la salida de algunos de sus líderes y fundan el Partido Nacionalista. Se consolidan las alianzas protagonistas de la escena electoral durante los siguientes 20 años: Republicanos y Socialistas; el Partido Unión de Puerto Rico y los Republicanos forman la Alianza Puertorriqueña; los Republicanos contrarios a la Alianza fundan en Partido Republicano Puro o Constitucional Histórico que formarían coalición con los socialistas. En 1932 las fuerzas en la oposición consiguen la mayoría, a pesar de maniobras institucionales como la modificación de la Ley Electoral para prohibir candidaturas comunes, decretada con el propósito de frenar el avance socialista. Tras la ruptura de la Alianza, el antiguo Partido Unionista pasa a denominarse Partido Liberal, al frente del cual se encuentra Luís Muñoz Marín. El Partido Nacionalista, el Independentista y el Comunista deciden no acudir a las urnas ante las pocas posibilidades que les ofrece el panorama electoral. El Partido Liberal se consolida como oposición. 


\section{$3^{a}$ Etapa: Surgimiento del PPD: de alta competitividad a partido dominante.}

Comienza la etapa más decisiva en la conformación del sistema de partidos en Puerto Rico. Las escisiones en las fuerzas partidistas en torno al status y la elección de los compañeros de pacto, provocarán el derrumbe de los partidos tradicionales del que surgirán las nuevas opciones. El Partido Liberal acoge tras el cambio de su cúpula directiva como postura oficial la estadidad. Esto provoca la expulsión de los seguidores autonomistas que fundan el Partido Popular Democrático en 1938. La misma ruptura se da en el Partido Socialista y en el Unión Republicana: sus expulsados formarían el Partido Laborista Puro y el Partido Unión Republicana Progresista respectivamente. Para las elecciones de 1940 los partidos se aglutinan de la siguiente manera: Republicanos y Socialistas; Unificación Puertorriqueña Tripartita: Laborista Puro + Liberales + Unión Republicana Progresista; y el PPD en solitario.

Para explicar el sorprendente avance del PPD no hay que obviar la buena relación de los Presidentes norteamericanos Roosevelt y Truman con Luís Muñoz Marín y sus estrechos vínculos con el Partido Demócrata durante su estancia en Nueva York. El líder del Partido Liberal y después del PPD, llegó a formar parte del círculo de confianza de Roosevelt, relación que se vio recompensada con el trato de favor en la implementación de los programas federales del New Deal en la Isla. El resto de las fuerzas políticas relanzaron la alianza tripartita, ahora bajo el nombre de Partido Unión Republicana Progresista, con el fin de anular la fuerza del PPD y su apoyo gubernamental. En las elecciones de 1948 se fija el panorama electoral que dominaría el siglo XX y XXI: nace en 1946 el Partido Independentista Puertorriqueño (PIP) y el Partido Unión Republicana Progresista cambia su nombre a Partido Estadista. El PPD gana de nuevo por mayoría absoluta y accede al ejecutivo insular al conseguir el puesto para gobernador (la modificación en 1947 de la Ley Jones establece por primera vez su carácter electivo). En la campaña de 1948 se afianza la tendencia que acompañó las contiendas del XIX: el recurso al miedo y las visiones catastrofistas de la independencia y la estadidad federada. De nuevo estadistas, socialistas y reformistas se unen en coalición para aprovechar las pocas ventajas que el sistema les permite obtener un solo representante. Con Muñoz Marín en el ejecutivo local y el dominio de los programas federales de desarrollo, tiene lugar el escenario de oportunidad política para el PPD que liderará el proceso de "solución" del status. Bajo la presidencia del demócrata Truman se aprueba la Ley 600 que provee un Gobierno Constitucional para Puerto Rico y la celebración de elecciones constituyentes. Nacionalistas, comunistas y reformistas liberales no concurren a las elecciones y los socialistas desaparecerán definitivamente. Tras las elecciones de 1952 y la aplastante victoria del PPD, se diseña el sistema político autonomista bajo la forma del Estado Libre Asociado (ELA) a la medida y forma del Partido Popular Democrático, heredero de las tradicionales aspiraciones autonomistas del viejo Partido Liberal del XIX.

El autonomismo del siglo XX ha sido la opción vencedora desde 1904 hasta 1952, ya sea en solitario o en coalición electoral, gracias al apoyo institucional de los gobernadores impuestos por EEUU. El lapso en que Republicanos y Socialistas alcanzan el poder se corresponde con los años de crisis y los efectos adversos de la Gran Depresión en la Isla. Comienzan entonces las políticas migratorias oficiales que sacan del país a miles de obreros y campesinos desempleados, y potencial electorado del Partido Socialista. Le prosigue una etapa de apoyo institucional del que es beneficiario el PPD, imagen visible del éxito desarrollista y que atrae a este sector de la población que inicio al estilo populista que dominará los años siguientes. El caciquismo burocrático que caracterizó el siglo XIX volvería a estar presente en la vida política puertorriqueña del siglo XX. 


\section{Los partidos políticos y la política del status: interacciones locales y metropolitanas}

Si en el siglo pasado los avatares del liberalismo español condicionaron la estrategia autonomista y delimitaron el curso de la reforma política en Puerto Rico, la interacción entre Demócratas y Republicanos norteamericanos sería decisiva en el nuevo período. En los primeros años, ni Republicanos, ni Demócratas consideraron el status de la Isla, sin embargo, el avance electoral del Partido Socialista Puertorriqueño-con importantes conexiones con el movimiento laboral en EEUU- condiciona el cambio de postura del Partido Demócrata, que promete la estadidad eventual. Años más tarde, se produce un giro inesperado en las posturas oficiales de los partidos metropolitanos. Sería la Administración republicana la que, traicionando su promesa de anexión, presionara al gobierno del PPD para que optara por la independencia. En 1956 se da un acercamiento de posturas y republicanos y demócratas apoyarían el ELA y así será hasta 1962 (especialmente tras el triunfo de la Revolución Cubana en 1959). Sin embargo, el sorprendente triunfo del recién creado Partido Nuevo Progresista en las elecciones de 1968 de tendencia anexionista, despertó los miedos en la guardia republicana y matizó de nuevo su postura, desde la estadidad eventual a "si ésa fuera la opción elegida por el pueblo de Puerto Rico". En la década de los $80^{\prime}$ s, los Republicanos, por imperativo del Consejo Nacional de Seguridad, abandonaron la promesa de estadidad eventual. En 1977, la Ley de Primarias Presidenciales en Puerto Rico inaugura esta etapa pintoresca, en la que los puertorriqueños podrían participar en el proceso interno de selección de candidatos presidenciales demócratas y republicanos ${ }^{1}$. La posibilidad del doble voto generó un hecho insólito: los anexionistas puertorriqueños votaban por republicanos y demócratas. Una indefinición ideológica que se materializó en la figura del "burrofante" (mezcla de las insignias de los partidos estadounidenses). Las primarias presidenciales se desprendían del contenido ideológico metropolitano y eran cooptadas por la dinámica de la contienda local (García Passalacqua 1980). El burrofante ejemplificaba una vez más, la solución intermedia que parecía formar parte de la cultura política de los puertorriqueños. Este mecanismo, lejos de lograr la inclusión de los dos sistemas, obligó a Demócratas y Republicanos en 1996 a considerar la independencia.

\section{Conclusiones}

\section{¿Existe un verdadero eje de competencia?}

A partir de 1948 y tras el colapso de las opciones partidistas, el panorama político puertorriqueño se estabiliza: PPD, PER y PIP serían las fuerzas políticas protagonistas organizadas en torno al eje del status. Autonomismo, anexión e independencia se presentarían ahora como ideologías perfectamente vertebradas, sin embargo, los vaivenes experimentados en el pasado y su indefinición en cuanto a la solución final, seguirán tras la institucionalización de la reforma política autonomista en 1952. En este reducido escenario de apariencia de soberanía, los partidos políticos isleños pasarán a ser simples maquinarias de patronazgo interesadas en administrar la limitada estructura del gobierno local (Meléndez Vélez 1998:5). Esto ha caracterizado una política pública continuista y sin ruptura que ha reducido la aparente polarización en torno al principal eje de competencia: la relación con la metrópoli. El análisis de la retórica del status, llevó a Rivera (1996) a concluir que el autonomismo era más que una ideología, una categoría de comportamiento que había convertido a anexionistas proamericanos y a independentistas en perfectos estadolibristas conservadores. La evolución ideológica del PPD desde el independentismo, pasando por el autonomismo transitorio en 1952, al autonomismo con carácter permanente en 1956, tiene su razón de ser en la necesidad de establecer sólidas bases económicas que sirvieran de sustento a la autonomía política. La colaboración con el Gobierno de Roosevelt fue decisiva para conseguir la solvencia que financiase su programa 
populista de justicia social, en el que como él mismo expresó en las campañas electorales de 1940 al 44, el status no estaba en disputa. Luís Muñoz Marín expulsó a los independentistas del partido, acusándoles de provocar el desastre económico y de sabotear el incipiente milagro económico del modelo desarrollista puertorriqueño. Este viraje ideológico sin escisiones, fue posible gracias a su habilidad propagandística, su estilo carismático y su autoridad absoluta sobre el partido. Él mismo se atribuía el haber descubierto la "tercera vía: la puerta de salida de la situación colonial" (Anderson 1970: 83).

El sistema electoral es el elemento institucional decisivo para la estructuración de las preferencias del electorado y de los sistemas de partidos (Nohlen 1994). Sin embargo, en este especial contexto de dependencia, ha sido un instrumento legitimador y un punto de veto. El estudio de las raíces históricas de los avatares del autonomismo permiten comprender la situación de inmovilismo político y estancamiento actuales. El empate técnico entre las dos fuerzas mayoritarias ha convertido al sistema político puertorriqueño en un bipartidismo estable, en el que la alternancia responde al escaso margen de los electores para expresar su grado de satisfacción. Las peculiaridades del sistema electoral dejan pocas posibilidades a terceras fuerzas políticas y se ha consolidado el voto útil, conocido como "melonismo"2. El juego político queda en manos de los dos partidos que se han caracterizado por evitar de una forma institucionalizada la solución al problema del status. Esta indefinición ha pasado a formar parte de la cultura política de los puertorriqueños y tiene reflejo en frases tan populares como "lo mejor de los dos mundos" y fenómenos peculiares como los "burrofantes" y "ninguna de las anteriores".

Como ha quedado expuesto, los partidos políticos han estado imposibilitados estructuralmente para resolver la problemática en torno a la cual se han posicionado. El reparto de los puestos de la burocracia es el fin y la razón de su existencia y para ello, la distribución de las ayudas federales y la identificación de las obras públicas con el partido es la estrategia para atraer al electorado. La continuidad y la similitud de las políticas públicas han sido aplastantes: la política de incentivos económicos para atraer a las empresas norteamericanas, ha sido el eje de la campaña política del PPD. Con la alternancia en 1968 -en un contexto de crisis del modelo desarrollista-, el Partido Nuevo Progresista defensor de la anexión, no ha hecho más que continuar con la política reformista sin ruptura, pues no ha hecho nada por asumir las responsabilidades fiscales y económicas que la estadidad federada conlleva. Todo lo contrario, sus administraciones han consolidado el ELA de 1952, incluso en las campañas electorales uno de sus eslóganes fue "Estadidad para después", dejando claro que no era un asunto prioritario.

La misma ambigüedad se observa en el Partido Independentista (PIP). Su base electoral ha estado formada por profesionales liberales e intelectuales, que con su discurso catastrofista sobre el desastre económico si la Isla continuaba en situación de dependencia colonial, alejó a las clases trabajadoras, que disfrutaban de los cupones de alimentos y demás ayudas del welfare. Por tanto, el dilema político entre estadidad e independencia se ha transformado por consenso y pragmatismo en la necesidad de mantener los niveles de autogobierno compatibles con la seguridad económica. Y la misma dinámica se observa en relación a los plebiscitos celebrados. Las supuestas consultas definitivas sobre la solución transitoria, han sido una constante, con efecto legitimador del sistema. Ninguno de los tres plebiscitos celebrados en 1967, 1993 y 1998, ha resuelto el asunto del status político de Puerto Rico. El último de los cuales escenificó la parálisis institucional en la solución de autogobierno que viene arrastrando la Isla desde principios del siglo XX. La opción "Ninguna de las anteriores" resultó vencedora sobre las tres opciones clásicas. El PPD, defensor de la autonomía estadolibrista, decidió arrastrar a su electorado hacia esta fórmula ambigua y 
paralizante, con la que culmina un proceso de eterno retorno, Ninguna de la anteriores $(50 \%)$, Estadidad (46.5\%), Independencia (4.4\%) Estado Libre Asociado Territorial $(0.1 \%)$ y Libre Asociación (0.3\%). Ninguno de los plebiscitos de la década de los 90 ha contado con el respaldo del Congreso de los Estados Unidos y se han celebrado en base a leyes locales. De nuevo, los partidos políticos han formado parte del juego de la apariencia de soberanía para solucionar un problema que ni pueden ni quieren abordar. De esta manera, el plebiscito ha pasado a ser un instrumento más de expresión y legitimación del sistema. La victoria de "ninguna de las anteriores" en 1998 y el casi empate de la opción estadista zanjaba la política del status y se convertía en peligroso precedente de lo que años más tarde tendría lugar en la Isla: la parálisis institucional de 2006. Tras las elecciones de 2004, el ejecutivo quedó en manos de los autonomistas del PPD y las dos Cámaras en manos de los estadistas del PNP. La imposibilidad de sacar adelante la Ley de Presupuestos retenida en el Senado, desató la crisis fiscal y el cierre de las dependencias públicas. Durante el período en el que el país estuvo paralizado, el Estado sólo prestó servicios de urgencia en salud y seguridad. El mayor de los peligros del presidencialismo se cumplía en la Isla En "The perils of Presidentialism" (1990) y La quiebra de las Democracias (1985), J.J. Linz se posicionará a favor del Parlamentarismo, dando así inicio a un debate que ha dividido a la academia en cuanto a la conexión causal entre estructura institucional, forma de gobierno y estabilidad democrática. La parálisis institucional en situaciones de gobierno dividido es uno de los peligros del Presidencialismo señalados por Linz.

\section{Notas}

${ }^{1}$ Esta Ley permitía a los puertorriqueños participar en las primarias internas, pero no así, votar en las presidenciales. Es por ello, que en 1978 el Tribunal Supremo de Puerto Rico declaró inconstitucional el uso de fondos públicos para las primarias estadounidenses ya que no tenían un fin público.
${ }^{2}$ Un water melon (sandía en español): verde por fuera (color identificativo de los independentistas), pero rojo por dentro (color de los autonomistas).

\section{Referencias}

Anderson, R. (1998). Política Electoral en Puerto Rico. Puerto Rico: Editorial Plaza Mayor.

Anderson, R. (1970). Gobierno y partidos politicos en Puerto Rico. Madrid: Editorial Tecnos.

Bayron, T. (1988 y 2003) Elecciones y partidos políticos en Puerto Rico 1809-2000. Puerto Rico: Editorial Isla.

Cruz, M. (1955). Noticia y pulso del liberalismo puertorriqueño del siglo XIX. México: Editorial Orión.

Cubano, I. (2000) "Reformas electorales y práctica política en Puerto Rico". En Legitimidad, representación y alternancia en España y América Latina: las reformas electorales (1880-1930). Fondo de Cultura Económica.

D’alzina. C. (1995) Evolución y desarrollo del autonomismo puertorriqueño: siglo XIX. San Juan: Universidad Politécnica de Puerto Rico.

Domínguez, J. (1887). La autonomía administrativa en Puerto Rico. Mayaguez: Tipología Comercial.

Estades, F. (1988). La Presencia militar de Estados Unidos en Puerto Rico: 18981918. Intereses estratégicos y dominación colonial. Puerto Rico: Ediciones Huracán.

García, M. (1982). A. La política española en Puerto Rico durante el siglo XIX. Río Piedras, Puerto Rico: Editorial de la Universidad de Puerto Rico. 
García,J. (1988). "Partidos puertorriqueños y partidos estadounidenses". En Política Electoral en Puerto Rico. Puerto Rico: Editorial Plaza Mayor.

Garrido, M. (2004). "La reforma electoral de 1890". En Violencia y Legitimidad. Política y revoluciones en España y América Latina (1840-1910). Universidad de Cantabria.

Grosfoguel, R. (1999). "Antipatía frente a la soberanía. Lógicas globales y colonialismo en Puerto Rico", en Revista Nueva Sociedad, 161, pp 19-34.

Immergut, E. (1982). Health politics: interests and institutions in Western Europe. Cambridge, Massachusetts: Cambridge University Press.

Luque de Sánchez, M.D.(1986). La ocupación norteamericana y la Ley Foraker: la opinión pública puertorriqueña 18981904. Puerto Rico: UPR.

March , J. \& Olsen, J. (1984). "The New Institutionalism: Organizational Factors in Political Life". En American Political Science Review, N ${ }^{\circ} 78$.

Meléndez, E. (1998a). "Partidos y elecciones". En ANDERSON, R.W. Politica Electoral en Puerto Rico. Puerto Rico: Editorial Plaza Mayor.

Meléndez, E. (1998b). Partidos, Política Pública y Status en Puerto Rico. San Juan Puerto Rico: Ediciones Nueva Aurora.

Nonhlen, D. (1994). Sistemas electorales y partidos politicos. México: Cultura Económica.
Pagán, B. (1961).Procerato puertorriqueño del siglo XIX: Historia de los partidos politicos, desde sus orígenes hasta 1898. Puerto Rico: Editorial Campos.

Pantojas, E. (1990). Development Strategies as Ideology: Puerto Rico's Export Led Industrialization Experience. Boulder: Lynne Reiner.

Peters, G. (2003). El nuevo institucionalismo: la teoría institucional en ciencia política. Barcelona: Gedisa.

Rivera, A. (1996). Puerto Rico: Ficción y mitología en sus alternativas de status. Puerto Rico: Ediciones Nueva Autora.

Schedler, A. (2002)."The nested game of democratization by elections". En International Political Science Review, Vol. 23, no.1, pp.103-122.

Suárez Cortina, M. (2003). "Las tradiciones culturales del liberalismo español, 18081950". En Las Máscaras de la Libertad. El liberalismo español 1808-1950. Fundación Práxedes Mateo Sagasta. Madrid.

Thelen, K. \& Seteinmo, S. (1992)."Historical institucionalism in comparative politics". En Structuring Politics: Historical Institucionalism in Comparative Analysis.

Varela, P. (2006). "Un eterno dilema de status". En Puerto Rico ¿Autodeterminación huracanada?, Madrid: CAPRE. 